\title{
Type Toyota Management Systems (MSTT) of Small and Medium-Sized Enterprises in Mechanical and Electrical Industry
}

\author{
Stefan Kluge, Andreas Rau, and Engelbert Westkämper \\ Institute of Industrial Manufacturing and Management (IFF), University of Stuttgart, Nobelstr, \\ 12, D-70569 Stuttgart, Tel.: +49 (0)711 / 685-61862; Fax: +49 (0)711 / 685-51862 \\ sjk@iff.uni-stuttgart.de \\ www.iff.uni-stuttgart.de
}

\begin{abstract}
This paper gives an overview and considers the most recent aspects of a study, dealing with the topic of Type Toyota Management Systems. In the survey SMEs in mechanical and electrical industry have been asked. On the one hand, a questionnaire for a mass evaluation was used and on the other hand specialists have been interviewed orally for the specific evaluation. The paper shows the methodology of the survey and some of the highlights of the results. Additionally, some approaches to face future challenges are introduced.
\end{abstract}

Keywords: Production Systems, Lean Management, Holistic Production Design.

\section{Introduction}

Since basic conditions, such as shorter technology and product life cycles, are changing faster and faster, and due to increasing globalization and growing dynamics of the markets, the requirements for enterprises have increased with regard to product and service quality. Due to the worldwide growing competition, enterprises are faced with a stronger pressure. The companies' tasks are frequently hard to accomplish with conventional organizational methods $[1,2]$. At the beginning of the nineties of the last century, the "International Motor Vehicle Program" of the M.I.T. in Cambridge aroused automotive industry in Germany and Europe [3]. The use of production systems was proven in studies [8,9] and in practice [5, 6] and is qualitatively visible through downsizing the process chains. The profit potentials developed with holistic production systems are remarkable and quantified in practice with the following details: Increasing productivity by an average of $40 \%$, reduction of processing time by an average of $60 \%$, and stock minimizing by an average of $40 \%$. With the keyword Lean Production, the American scientists Womack, Jones und Roos describe the method of automotive production which they had seen in the Toyota company in Japan in their book "The machine that changed the world" [4, 5]. They write about the effective and quality-oriented production which looms large for competitiveness, management concepts like the integrated production system or Lean Production were introduced in enterprises [5,6]. These concepts mainly exist in automotive enterprises and also in large companies from other sectors. They rarely exist in SME [7]. 


\section{Study in Type Toyota Management Systems}

Type Toyota Management Systems (MSTT) are management approaches such as the Toyota production system, holistic production systems, lean production, business reengineering or management concepts which contribute a positive approach to the changing market conditions. MSTT are still focused on the automotive and supply industry. MSTT are predominantly used in large enterprises and only slowly arrive in other industries. Due to the fact that in branches like the mechanical and electrical industry only less experience and awareness had been documented the Institute of Industrial Manufacturing and Management of the University of Stuttgart realized a study. Relating to enterprise typological classifications, leading enterprises develop customer-specific products, standardized products with customer-specific variants as well as standard products with variants $(86 \%)$. Standard products with variants only exist in a minority of the surveyed enterprises of the mass evaluation. The leading enterprises apply manual (51\%), industrialized (71\%) and also automated work techniques. However, the enterprises surveyed in the mass evaluation apply only $21 \%$ automated work techniques. The leading enterprises supply a high product variety, work mainly with automated processes and have a highly standardized product range. These are aspects of the leading position of enterprises of the specific evaluation. The following questions in this study were to be answered from the perspective of science and practice:

- What is the actual state of MSTT? Holistic production systems and management concepts have been analyzed which have potential to develop substantial solutions for new and changing challenges

- Which methods and tools are included in effective MSTT? Examples from automotive industry show that methods and tools like Just-in-Time-Logistic (JIT), the continuous improvement process (CIP), the process standardization and the visual management belongs to MSTT [11]

- Are there any enterprise-specific conditions for the usage of MSTT?

- Which general conditions are important for the success of MSTT?

- What should MSTT be able to do in future apart from what they can do today?

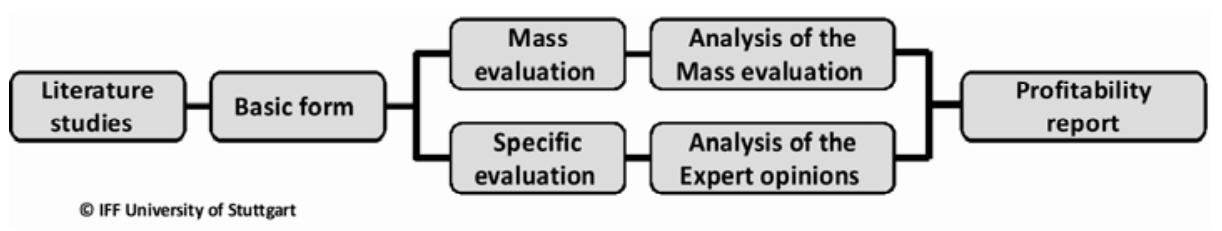

Fig. 1. Research design (IFF, University of Stuttgart)

Based on literature studies which cover the current research and practice status a basic form was developed (figure 1). In this basic form all relevant questions were summarized in a question pool, including open and closed questions. For getting funded data and information, a combined procedure with extensive surveys (mass evaluation) and several detailed expert opinions in the form of interviews (specific 
evaluation) were chosen. In the mass evaluation more than 100 enterprises within the mechanical and electrical industry were interviewed. The specific evaluation covers so-called leading enterprises which come from the target group and have experience within the scope of the MSTT. In a conclusive step, the results were consolidated and prepared for the report.

\subsection{Mass Evaluation}

The majority of the polled enterprises follow the trend of the big companies which often belong to the automotive industry with a time gap to implement MSTT.

Approximately $20 \%$ of the enterprises have planned "no implementation". Almost $50 \%$ of the enterprises have started with the implementation later than 2005. The implementation of such systems started in the automotive industries from the beginnings up to the mid-nineties of the previous century. For a few years now MSTT has been in the improvement and optimization phase $[6,7]$. Contrary to this situation, enterprises which are actually implementing MSTT are in the starting phase.

\subsubsection{Specific Tools of Work Organization}

The methods of the work organization (figure 2) are consistently often implemented and applied, which is an argument for these methods. Analyzing the results of the survey, the methods of "Job-Enlargement", "Job-Enrichment" and "Job-Rotation" are less often used than expected according to their degree of popularity. The same is true for the method "ergonomic evaluation of operating processes". The target of these four methods is to improve the working conditions for employees in assembly. There are important aspects in comparing the success and the implementation of these methods. For example, many enterprises mention "flexible working hours" as very

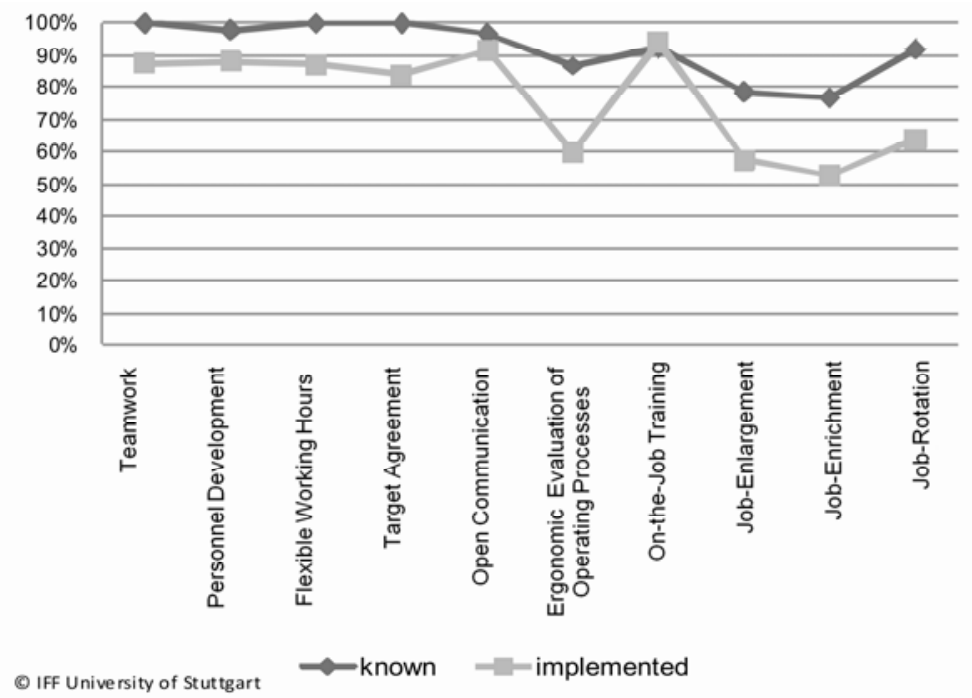

Fig. 2. Popularity and implementation of methods of work organization (IFF, University of Stuttgart) 
successful. Accordingly, this tool is implemented very often. The method "ergonomic evaluation of operating processes" is in a completely different situation. This method is mostly seen as successful but the implementation is only realized by few of the interviewed enterprises [10].

For "Job-Enlargement", "Job-Enrichment" and "Job-Rotation" the above mentioned effect is even stronger, so that not used potentials could be identified.

\subsubsection{Specific Tools of CIP and TQM Methods}

Analyzing the methods of the CIP (continuous improvement process) and TQM (total quality management) it can be stated that "Six-Sigma" and "Line-Stop Concept" are well-known but rarely used. Regarding the evaluation of the CIP and TQM methods, it shows that some methods are categorized as successful but the implementation is rarely mentioned (figure 3).

"Poka-Yoke" and "Fast Problem Detection and Resolving" are also well-known and evaluated as very successful. At the same time the implementation of "PokaYoke" is not very distinct. The implementation of "Fast Problem Detection and Resolving" is on a higher level.

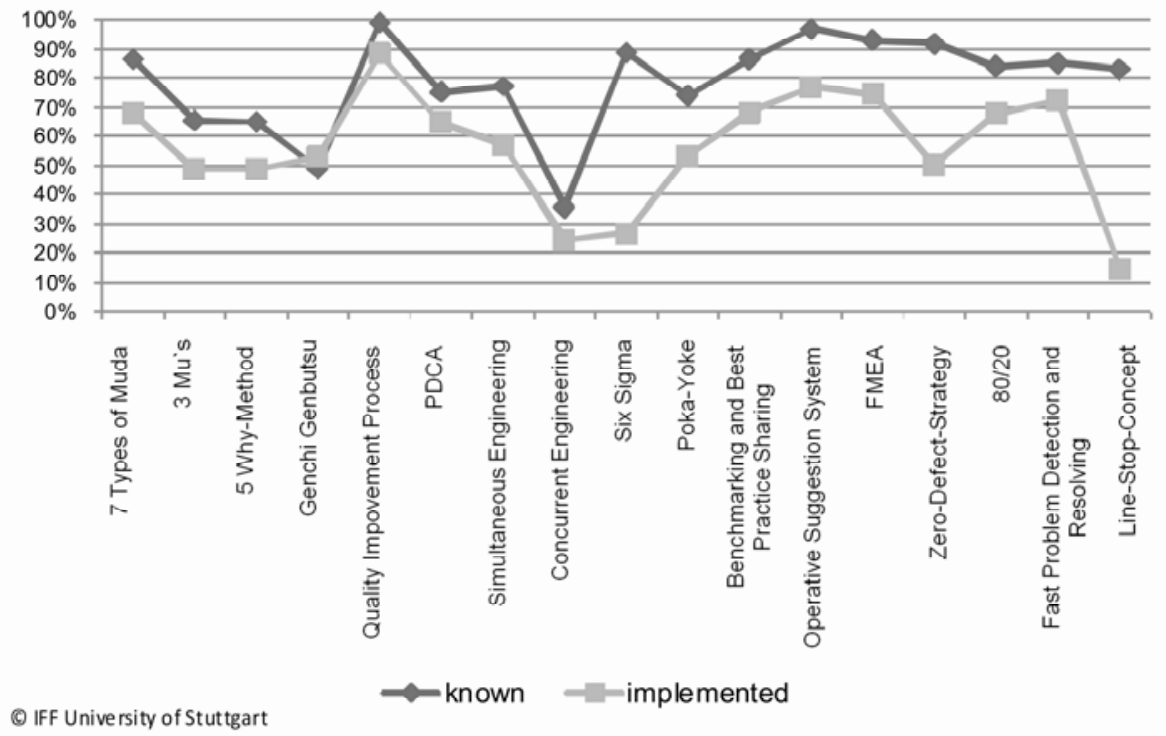

Fig. 3. Popularity and implementation of CIP and TQM methods (IFF, University of Stuttgart)

An important aspect of the survey results are the mentioned most successful methods. In the sector of the target group there is no method which accords to all requirements and could be universally used for all ranges of application. This means that each enterprise has to develop an individual package of methods to get the expected benefit after a successful implementation. The base for such a package should be universally usable methods like " $5 \mathrm{~S}$ or rather standardized clean-up". 
The result of the mass evaluation to methods which can support MSTT in enterprises (multiple choices were possible) is a ranking of the most important methods. The two main methods are "exchange of experiences with the partners" and "special implementation guide for SME".

\subsection{Specific Evaluation}

The majority of the leading enterprises have started with the implementation of MSTT later than 2001. $43 \%$, however, started between 1990 and 2000. The realization and implementation level in enterprises is very high. More than half of the enterprises have implemented more than $50 \%$ of their MSTT. The results show, that the interviewed enterprises have good experience within the scope of the MSTT, through early introduction and extensive implementation.

\subsubsection{Specific Tools of Production Control}

The specific tools of production control have been analyzed concerning their usability from the experts' point of view. In these interviews the "Pull-System" has been identified as well-known and as an important method. But still this method has been evaluated to $100 \%$ as "little", respectively "rather little" realized. The same applies for the methods of "synchronized production", "value stream design" and "flow production". The indicators of "relevance" and "realization" of "Just-in-Time" are relatively balanced.

\subsubsection{Specific Tools of Robust Processes}

The evaluation of the methods of "robust processes" based on experts interviews shows for "Jidoka" that the implementation and application is to $100 \%$ specified as being "little", although it is rated as rather important by $75 \%$. The like applies for other methods like "standardized methods and processes" and "supplier standardization". This means that enterprises see high potential for these methods.

\subsubsection{Specific Tools of Visual Management}

The methods of visual management are known by $100 \%$ of all specialists but this is no guarantee for a successful implementation in the enterprises. A good example is the method "standardized clean-up at a workplace". Although it has a high relevance $(80 \%)$ and a high degree of notification, the implementation rate is rather small. Similar values and relations are evaluated for "Andon-Boards" and "lettering on bottom, marking und labeling" or "communication boards".

The leading enterprises have identified the two methods "exchange of experiences with the partners" and "implementation guide especially for small and medium-sized enterprises" as especially important for the support for the realization of the MSTT.

\subsection{Comparison between Mass and Specific Evaluation}

The question whether the interviewed enterprises from the target group are actually leading enterprises, was to be answered through the comparison of the essential results from the mass and specific evaluation. Also it was to be analyzed, how leading enterprises are characterized. Therefore, all relevant similarities and differences from 
the interviewed enterprises were compared in this study with the results of the mass evaluation.

The enterprises of the mass evaluation for the most part $(40 \%)$ use individual methods from a MSTT. The leading enterprises, however, confirm their special position by the implementation of complete systems. Additionally, the leading status of the interviewed enterprises can be established with the implementation of MSTT with $43 \%$ between 1990 and 2000 and $57 \%$ between 2001 and 2005 and the fact that the degree of implementation of MSTT in enterprises is not smaller than $10 \%$. However, $45 \%$ of the enterprises from the mass evaluation have started with the implementation after 2005 and $22 \%$ see the degree of the realization smaller than $10 \%$. $50 \%$ of the suppliers are involved in the MSTT according to enterprises from the mass evaluation but this is true for only $29 \%$ of the enterprises of the specific evaluation. The analysis of the used methods shows that the percentage distribution of the differences between the general popularity and the actual implementation of individual methods is nearly identical in enterprises of the mass and the specific evaluation. Differences exist especially in methods like Just-in-Time, One-piece-flow, flow shop, synchronic production, supplier standardization, Six Sigma, Poka-Yoke or Line-stop-concept / trigger line which require a higher standardization level and/ or implementation effort. It seems that it is more complicated to implement these methods in enterprises of the target group than in the automotive industry. The popularity and the actual implementation of CIP and TQM methods are relatively high in both the mass and specific evaluation. This indicates that the target group chooses selectively generally known methods instead of all existing methods. The methods of work organization and business culture/environment were both mainly used in the target group and in the enterprises of both evaluations. To identify the reasons for the low realization level of the MSTT in the target groups, the enterprises were asked about potential barriers. "Limited personnel resources" and "work overload high performer" were mentioned as the highest barriers in the interviews. The enterprises in the mass and specific evaluation agree on the fact that business culture and support from the management facilitates the implementation of MSTT. Essential is the participation of the employees. The integration of the employees is the core aspect which underlines the leading role of the interviewed enterprises. This is confirmed by the fact that the leading enterprises use a bigger spread of learning styles to convey MSTT to their employees.

\subsection{Study Results}

The aim of this study was to analyze the level of experience and developmental status of MSTT within the target group for SME. The mass evaluation was necessary to show the level of experience of a high number of enterprises in comparison to enterprises with proven know-how. Through the specific evaluation, the core questions could be considered in detail with the leading enterprises [12].

The study could prove with the results of the expert discussions by the leading enterprises, that the implementation of MSTT could be successful in the target group. The leading enterprises are working actually on the further development of their MSTT. However, many enterprises are in the implementing phase of their first MSTT. 67\% of the enterprises from the mass evaluation are planning or implementing an MSTT today. Only $11 \%$ say that they have already finished the implementation. 
The importance of this topic is obvious because $79 \%$ of the enterprises are working on the implementation of a MSTT. By the comparison with the leading enterprises, less successful users of MSTT can identify potentials for their own further MSTT and use the leading enterprises for orientation. They have potentials in the administrative, development and service fields. The study shows that the use of MSTT in the enterprises, can lead to success and can receive and improve their competitiveness. Thus, there is need for action for the interviewed enterprises. They need instruments to be able to control an MSTT with little effort. According to the results of the interviews, the enterprises mainly require more exchange of experiences with partners from industry, a major regard of the general conditions of SME and special adaptive solutions of MSTT. The main potentials, for the target group as well as for enterprises of other industries in Germany, are a stronger integration of the employees, a better management support, and an enterprise-specific adaptation of MSTT. Therefore, business culture has to change substantially. In summary, the study results confirm the benefit of MSTT in enterprises of the interviewed group. The implementation should be less complex and regard the enterprise-specific circumstances.

\section{Forecast}

In the specific evaluation the enterprises had been asked "what MSTT should be able to do in the future, where they are unfit today" and "where the unexhausted applications" are. These questions are the base for the following optimization potential of MSTT:

The management has to be committed stronger to the MSTT, methods have to be designed easier, MSTT should be adaptive to enterprise-specific circumstances, prove integration of employees and customers and better preserve resources. Potential exist in administration, in the supplier integration, in development and service.

For the future, it will be necessary to develop branch and firm-specific solutions. Therefore, the characteristic basic conditions of the interviewed enterprises must be considered. However, the further question shouldn't be how to reproduce Toyota, but rather "What is beyond Toyota?" Already today researchers and increasingly also enterprises in Germany and Europe concentrate on this question. Production systems which are adaptive for the site-specific requirements are necessary. For the long-term protection of Europe and Germany as a location for manufacturing industry, a further development to a knowledge-based production system is essential. Based on this, the idea of a European production system occurred [2, 3]. This advanced knowledgebased production system, has to be beyond the scope of the typical aspects from the TPS. It has to be adjusted to the structures of transformable production, without renouncing the benefits of the TPS $[1,3]$. Modern production systems must regard that production takes place in global networks. The sustainable and efficient usage of resources such as energy, air, water and finally the employees should be a part of the production system and thus the base for middle and long-term strategic decisions [2, 3]. The application of all value added potentials demand a relevant build-to-order strategy and also the integration of modern ICT- technologies, to exploit strategic and long-term competitive advantages for production in Europe [2,3]. 


\section{References}

1. Westkämper, E., Zahn, E. (Hrsg.): Wandlungsfähige Produktionsunternehmen: Das Stuttgarter Unternehmensmodell. Springer, Berlin (2009)

2. Jovane, F., Westkämper, E., Williams, D.: The ManuFuture Road: Towards Competitive and Sustainable High-Adding-Value Manufacturing. Springer, Berlin (2009)

3. Womack, J.P., Jones, D.T., Roos, D.: The machine that changed the world: The Story of Lean Production. Harper Perennial, New York (1991)

4. Ditzer, R.: Toyota: Managementsystem des Wandels und Kultur der Verbesserung. Japan Markt, Wissenschaft und Praxis (2004); Köln (2005)

5. Ohno, T.: The Toyota Production System: Beyond Large-Scale Production. Productivity Press, Portland (1998)

6. Liker, J.: The Toyota Way: 14 Management Principles from the World's Greatest Manufacturer. McGraw-Hill, New York (2004)

7. Lay, G., Neuhaus, R.: Ganzheitliche Produktionssysteme (GPS) - Fortführung von Lean Production. Angewandte Arbeitswissenschaften 185, 32-47 (2005)

8. Lay, G., Dreher, C., Kinkel, S.: Neue Produktionskonzepte leisten einen Beitrag zur Sicherung des Standortes Deutschland. In: Mitteilungen aus der Produktionsinnovationserhebung, vol. 1. Fraunhofer ISI, Karlsruhe (1996)

9. Sautter, K., Meyer, R., Westkämper, E.: Mehr Erfolg durch professionellen Methodeneinsatz? Ergebnisse und Handlungsfelder einer empirischen Untersuchung des Fraunhofer IPA und des REFA-Verbandes in 226 produzierenden Unternehmen, Stuttgart und Darmstadt (1998)

10. Spath, D.: Ganzheitlich Produzieren - Innovative Organisation und Führung, LOGIS, Stuttgart (2003)

11. Feggeler, A., Neuhaus, R.: Ganzheitliche Produktionssysteme; Gestaltungsprinzipien und deren Verknüpfung. Institut für angewandte Arbeitswissenschaft, Wirtschaftsverlag, Köln (2002)

12. Westkämper, E., Kreuzhage, R., Hummel, V., Kluge, S., Wiese, S.: Managementsysteme vom Typ Toyota: In kleinen und mittelständischen Unternehmen des Maschinenbaus und der Elektroindustrie mit 100 bis 1500 Mitarbeitern. State of the art, Entwicklungs- und Erfahrungsstand, Forschungs- und Handlungsbedarf. Studie im Auftrag der KSB-Stiftung (KSB-Nr. 1254) Stuttgart, März (2008) 